\title{
Study on the Load Sharing Capability of Closed-loop Gear Transmission in Braiding Machine
}

\author{
Xianqing Lei ${ }^{1}$, Qi Meng ${ }^{1 .^{*}}$ and Wensuo $\mathrm{Ma}^{1}$ \\ ${ }^{1}$ Henan University of Science \& Technology, Luoyang, China \\ Corresponding author: 529566570@qq.com
}

\begin{abstract}
The static model is established based on the structural characteristics of closed loop gear transmission. The influence law of manufacturing and assembly error with load sharing coefficient was researched. The formula among transmission gear errors and load sharing coefficient is established. According to the formula of error coupling in the same angular frequency, transmission errors in closed loop gear transmission are coupled. The measure for reducing the transmission error is put forward. The study provides a theoretical basis for the design of high speed braiding machine.
\end{abstract}

Keywords. Braiding machine, closed-loop gears, load sharing coefficient, transmission error.

\section{Introduction}

The product of hose or cable has excellent property for tensile, bending, impact and wear by adding a layer or layers of mesh reinforcement layer. Mesh reinforcement layer is made by crossing the cable with each other [1-3]. Mesh reinforcement layer was often knitted by using knitting machine in order to realize cross cable with each other. The key part of the knitting machine is the mechanical drive system. Improving the transmission performance is part of the important ways to improve the speed and load of knitting machine. Currently, mechanical transmission system of the knitting machine is a closed-loop gear transmission at home and abroad. The closed-loop gear transmission is comprised of $n$ gears. The number of gears is even, $n \geq 4$. Drive chain is made by $n$ gears which are engaged with each two gears. If the closed-loop gear transmission exist transmission error, instantaneous ratio is changed. Asymmetric load distribution induces vibration and noise. The transmission stability of closed-loop gear transmission is reduced. Therefore, it is extremely important to study the relationship between transmission error and load.

The domestic and international scholars have done quite a lot of work on a transmission error and load sharing capability of closed-loop gear transmission. The transmission error is decreased by a modification gear profile, increasing manufacture and assembly accuracy [4,5]. But most academic researchers have focused on a pair of gears or open-loop gear transmission. Load sharing coefficient is put forward. The relationship between transmission error and load sharing coefficient is studied [6-8]. But most studies have focused on open-loop gear transmission like planetary gear transmission. There is less study on the load sharing capability of closed-loop gear transmission. Therefore, there has been a long lack of studies on the relationship between transmission and load sharing capability

The closed-loop gear transmission of knitting machine is investigated in this paper. According to the closed-loop gear transmission characteristic which is power split and converging, the static model of closed-loop gear transmission of knitting machine is established. The influence rule of manufacturing errors and assembly errors with closed-loop gear transmission is researched. According to the coupling formula of transmission error when the phase angle is the same, improvement measures are put forward to reduce the transmission error.

\section{The working principle of closed-loop gear transmission}

As figure 1 shows, power is input from input axis. Then the power is diverted to two power flows at the first gear. Each power flow transfers one-half of the load. The powers are confronted at the last gear. 


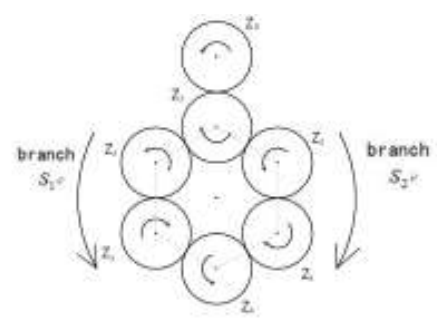

Fig.1 .Schematic diagram of closed-loop gear transmission.

\section{Influence factors of transmission error}

Gear error is part of the main reasons which induce the vibration. Therefore, the study of gear error is the most important thing. Gear error divided into two categories: and gears manufacture error and gear assembly error. The manufacture error mainly includes the gear eccentric error $F^{\prime}$ which leads to the asymmetric load distribution. The assembly error mainly includes the clearance $e_{1}$ between gear axle-hole and axle, the jumping value $e_{2}$ of the axis and the eccentric $e_{3}$ of bearing,which lead to the asymmetric load distribution.

\section{Influence factors of transmission error}

Equivalent mesh error is the projection of a manufacturing error and assembly error onto joggle line [9]. The direction of extending joggle line is positive, whereas its negative opposite. Taking manufacturing error $E_{i}$ as an example, figure 2 shows the schematic of an equivalent mesh error which is the projection of eccentricity errors onto joggle line. $E_{i}$ and $A_{i}$ are manufacturing and assembly error. The direction of transmission is which is the direction of gear 1 to gear 2.Pressure angle is $\alpha . \alpha_{i}$ and $\varphi_{i}$ i are the phase angle of a manufacturing error and assembly error. $\beta_{i j}$ is the angles between the direction of transmission and $\mathrm{x}$ axis when the direction of transmission is $i j . \gamma_{i j}$ is the angles between the joggle line and the $\mathrm{x}$ axis when the direction of transmission is $i j$.

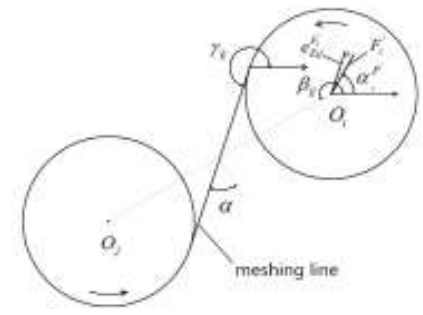

Fig.2. Schematic diagram of equivalent mesh error.

The equivalent mesh error of gear eccentric error $F^{\prime}$

$$
e_{i j}^{F_{i}^{\prime}}=-F_{i}^{\prime} \cos \left(\gamma_{i j}-\alpha_{i}^{F^{\prime}}-\omega t\right)
$$

The equivalent mesh error of clearance $e_{1}$ between gear axle-hole and axle

$$
e_{i j}^{e_{1}}=-e_{1} \cos \left(\gamma_{i j}-\alpha_{i}^{e_{1}}-\omega t\right)
$$

The equivalent mesh error of jumping value $\boldsymbol{e}_{2}$

$$
e_{i j}^{e_{2}}=-e_{2} \cos \left(\gamma_{i j}-\alpha_{i}^{e_{2}}-\omega t\right)
$$

The equivalent mesh error of eccentric $e_{3}$ of bearing

$$
e_{i j}^{e_{3}}=-e_{3} \cos \left(\gamma_{i j}-\alpha_{i}^{e_{3}}-\omega t\right)
$$


The equivalent mesh error of gear manufacturing error

$$
e_{E i j}=e_{i j}^{F_{i}^{\prime}}
$$

The equivalent mesh error of gear assembly error

$$
e_{A i j}=e_{i j}^{e_{1}}+e_{i j}^{e_{2}}+e_{i j}^{e_{3}}
$$

$e$ and $\omega$ are equivalent mesh error and gear speed.

\section{The static model}

The model of closed-loop gear transmission is as follow figure 3

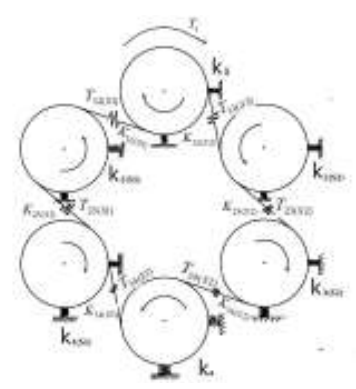

Fig.3. The model of closed-loop gear transmission.

The elastic deformation is represented by equivalent spring stiffness. $k_{i}$ is the equivalent spring stiffness of gear supporting. $K_{i j}$ is the meshing stiffness between gear i and gear j. Assuming the gear of output shaft doesn't rotation, gear $Z_{1}$ is applied a torque $T$. One of the gears which are $Z_{1}, Z_{2(S 1)} Z_{2(S 2)}, Z_{3(S 1)}, Z_{3(S 2)}$ and $Z_{4}$ first enter into meshing. Then the rest of gears has backlash. Finally all gears enter into meshing with the increasing torque $T$.

Considering the above analysis, the tooth surface load are set to $W_{i j(S 1)}$ and $W_{i j(S 2)}$

$$
\begin{aligned}
& W_{i j(S 1)}=K_{i j}\left(r_{i} \theta_{i}-r_{j} \theta_{j}-\Delta_{i j}\right) \\
& W_{i j(S 2)}=K_{i j}\left(r_{i} \theta_{i}-r_{j} \theta_{j}-\Delta_{i j}\right)
\end{aligned}
$$

$r_{i}$ and $r_{j}$ in the formula are the radius of base circle of gear i and gear j. $\theta_{i}$ and $\theta_{j}$ are the angular displacement of gear i and gear j. $\Delta_{i j}$ is equivalent mesh error.

The formula can be derived from formulas (1) (6) as

$$
\Delta_{i j}=\sum e_{E i j}+\sum e_{A i j}
$$

Due to the gear of output shaft doesn't rotation, the tooth surface load of output gear can be expressed as

$$
\begin{gathered}
W_{i j(S 1)}=K_{i j}\left(r_{i} \theta_{i}-\Delta_{i j}\right) \\
W_{i j(S 2)}=K_{i j}\left(r_{i} \theta_{i}-\Delta_{i j}\right)
\end{gathered}
$$

$W_{i j(S 1)}$ and $W_{i j(S 2)}$ in the formula are the tooth surface load of branch S1 and branch S2.

The load sharing coefficient $\Omega_{p}$ is defined as the ratio of the actual load and the ideal load, which reflects the deviate degree of the actual load with the ideal load [8]. 


$$
\begin{aligned}
& \Omega_{p}=\frac{W_{n \max }}{W_{n}}=\frac{W_{n}+\Delta W_{n}}{W_{n}} \\
& =1+\frac{\Delta W_{n}}{W_{n}}=1+\frac{K \sum \Delta_{i}}{T / r}
\end{aligned}
$$

$W_{n}$ is the ideal tooth surface load. $\Delta W_{n}$ is the error of tooth surface load.

\section{The analysis of the static load}

The figure 1, taking 6 gears as an example, shows the transmission principle. The power is input from input axis 0 . Then the power is diverted to two power flow at the gear $Z_{1}$. Finally the powers are confluented at the gear $Z_{4}$. The power is transferred from 2 independent branches. The branch $S_{1}$ comprises $Z_{1(S 1)} Z_{2(S 1)} Z_{3(S 1)} Z_{4(S 1)}$. The branch $S_{2}$ comprises $Z_{1(S 2)} Z_{2(S 2)} Z_{3(S 2)} Z_{4(S 2)}$. The main parameters of closed-loop gear transmission with 6 gears are shown in table 1 . The phase angle of error are shown in table 2.

Table 1. The main parameters of closed-loop gear transmission.

\begin{tabular}{ccc}
\hline & Branch $S_{1}$ & Branch $S_{2}$ \\
\hline Tooth number & 60 & 60 \\
Modulus $/ \mathrm{mm}$ & 5 & 5 \\
Tooth width $/ \mathrm{mm}$ & 200 & 200 \\
Pressure angle & $20^{\circ}$ & $20^{\circ}$ \\
Input speed (r/min) & \multicolumn{2}{c}{6000} \\
\hline
\end{tabular}

Table 2. The phase angle of error.

\begin{tabular}{clllll}
\hline & Gear & $\alpha_{i}^{F^{\prime}}$ & $\varphi_{i}^{e 1}$ & $\varphi_{i}^{e 2}$ & $\varphi_{i}^{e 3}$ \\
\hline \multirow{3}{*}{$\begin{array}{c}\text { Branch } \\
S_{1}\end{array}$} & $Z_{1(S 1)}$ & $25 \pi / 18$ & $25 \pi / 18$ & $25 \pi / 18$ & $25 \pi / 18$ \\
& $Z_{3(S 1)}$ & $15 \pi / 18$ & $15 \pi / 18$ & $15 \pi / 18$ & $15 \pi / 18$ \\
& $Z_{4(S 1)}$ & $25 \pi / 18$ & $3 \pi / 18$ & $3 \pi / 18$ & $3 \pi / 18$ \\
\hline \multirow{3}{*}{ Branch } & $Z_{1(S 2)}$ & $25 \pi / 18$ & $25 \pi / 18$ & $25 \pi / 18$ & $25 \pi / 18$ \\
$Z_{1(S 1)}$ & $Z_{2(S 2)}$ & $3 \pi / 18$ & $3 \pi / 18$ & $3 \pi / 18$ & $3 \pi / 18$ \\
& $Z_{3(S 2)}$ & $15 \pi / 18$ & $15 \pi / 18$ & $15 \pi / 18$ & $15 \pi / 18$ \\
& $Z_{4(S 2)}$ & $25 \pi / 18$ & $25 \pi / 18$ & $25 \pi / 18$ & $7 \pi / 18$ \\
\hline
\end{tabular}

The manufacturing error and assembly error are $50 \mu \mathrm{m}$. The change curve of load coefficient is shown in figure 4 when it is influenced by individual error.
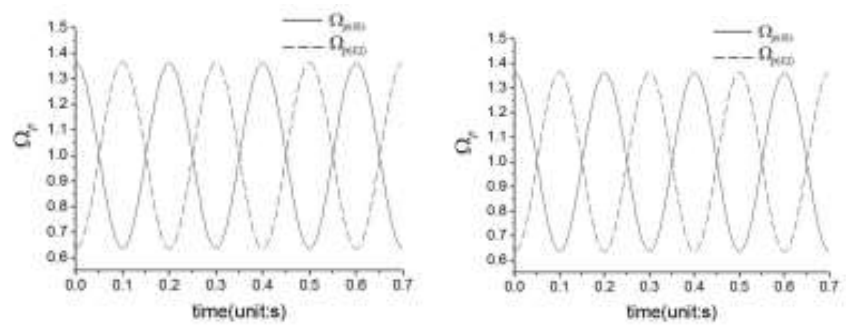
(a) Individual effect of $F^{\prime}$

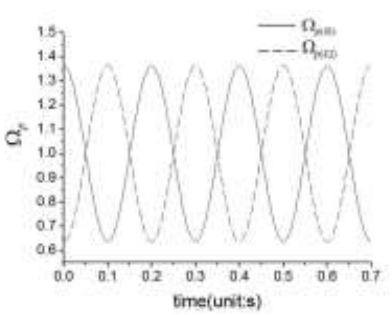

(c) Individual effect of $e_{2}$ (b) Individual effect of $e_{1}$

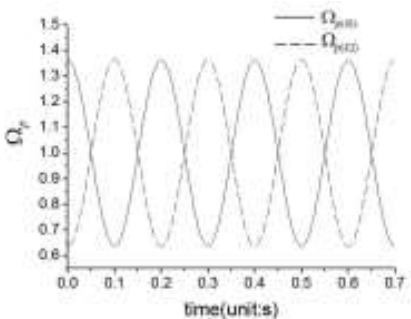

(d) Individual effect of $e_{3}$

Fig.4. The change rule of load sharing coefficient.

The figure 4 shows the change curve of each error is same when the initial phase is the same. Actually, manufacturing error and assembly error are not equal. Each error randomly appears in the design standard. Manufacturing error and assembly error are shown in table 3 . The change curve of load coefficient is shown in figure 5 when it is jointly influenced by all errors.

Table 3. The phase angle of error. $\mu m$

\begin{tabular}{cccccc}
\hline & Gear & $F^{\prime}$ & $e_{1}$ & $e_{2}$ & $e_{3}$ \\
\hline & $Z_{1(S 1)}$ & 140 & 4 & 5 & 15 \\
Branch & $Z_{2(S 1)}$ & 133 & 5 & 3 & 13 \\
$S_{1}$ & $Z_{3(S 1)}$ & 136 & 6 & 3 & 13 \\
& $Z_{4(S 1)}$ & 145 & 3 & 4 & 11 \\
\hline \multirow{3}{*}{ Branch } & $Z_{1(S 2)}$ & 140 & 4 & 5 & 15 \\
$S_{2}$ & $Z_{2(S 2)}$ & 136 & 4 & 5 & 15 \\
& $Z_{3(S 2)}$ & 133 & 5 & 4 & 10 \\
& $Z_{4(S 2)}$ & 145 & 3 & 4 & 11 \\
\hline
\end{tabular}

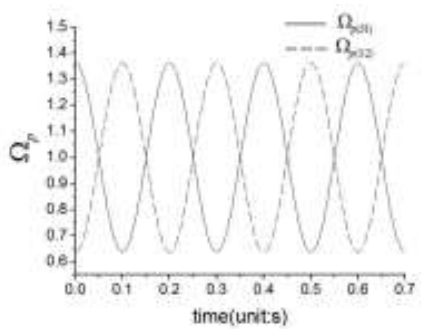

Fig.5. The change rule of load sharing coefficient.

The conclusion can be shown from the figure.

(1)The load sharing coefficient of each branch of closed-loop gear transmission show periodic changes.

(2)The maximum load sharing coefficient of branch S1 and branch S1 are 1.3625 and 1.3631.

(3)Through comparing the change rules of load sharing coefficient, the loading coefficient of two branches are not synchronized. Maximum instantaneous coefficients of each branch are also different.

\section{Transmission error coupling}

Due to the transmission features of closed-loop gear transmission, the calculation formula for the transmission error is derived. According to the principle of coupling errors, the error of closed-loop gear transmission is coupled, as showed in table 4 . The change curve of load coefficient is shown in figure 6 when the error of closed-loop gear transmission is coupled. 
Table 4. The phase angle of error.

\begin{tabular}{cccccc}
\hline & Gear & $\alpha_{i}^{F^{\prime}}$ & $\varphi_{i}^{e 1}$ & $\varphi_{i}^{e 2}$ & $\varphi_{i}^{e 3}$ \\
\hline & $Z_{1(S 1)}$ & $7 \pi / 18$ & $-11 \pi / 18$ & $-11 \pi / 18$ & $7 \pi / 18$ \\
$\begin{array}{c}\text { Branc } \\
\text { h } S_{1}\end{array}$ & $Z_{2(S 1)}$ & $15 \pi / 18$ & $-3 \pi / 18$ & $-3 \pi / 18$ & $15 \pi / 18$ \\
& $Z_{3(S 1)}$ & $3 \pi / 18$ & $-15 \pi / 18$ & $-15 \pi / 18$ & $3 \pi / 18$ \\
& $Z_{4(S 1)}$ & $25 \pi / 18$ & $7 \pi / 18$ & $7 \pi / 18$ & $25 \pi / 18$ \\
\hline $\begin{array}{c}\text { Branc } \\
\text { h } S_{2}\end{array}$ & $Z_{1(S 2)}$ & $7 \pi / 18$ & $-11 \pi / 18$ & $-11 \pi / 18$ & $7 \pi / 18$ \\
& $Z_{3(S 2)}$ & $15 \pi / 18$ & $15 \pi / 18$ & $15 \pi / 18$ & $-3 \pi / 18$ \\
& $Z_{4(S 2)}$ & $25 \pi / 18$ & $7 \pi / 18$ & $7 \pi / 18$ & $25 \pi / 18$ \\
\hline
\end{tabular}

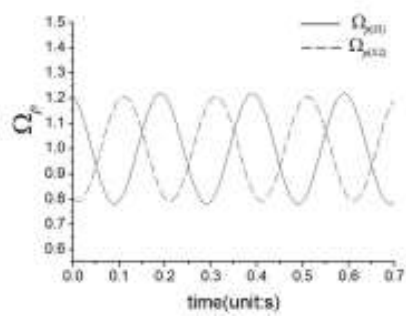

Fig.6. The change rule of load sharing coefficient.

The maximum load sharing coefficient of branch S1 and branch S1 after coupled are 1.2192 and 1.2073. The load sharing coefficient of closed-loop gear transmission has been reduced.

\section{Conclusion}

(1)The load sharing coefficient of closed-loop gear transmission have an obvious characteristic of periodic changes.

(2)According to the error accumulation, the load sharing coefficient under individual error effect is smaller than under common error effect

(3)The equivalent mesh error of every gear has the same effect on the load sharing coefficient

(4)According to the method of coupling, the load sharing coefficient of closed-loop gear transmission can be reduced. The transmission stability is improved.

\section{References}

1. P. Zhang, L. J. Gui, Z. J. Fan: The Experimental Study of Absorption Property for the Woven Fabric Composite Material Circular Tubes. Journal of Composite Materials, 2007, 01:146-150.

2. D. Q. Gu, L. Nie: Braiding Machine of Mesh Reinforcement Layer for the Plastic Pressure Hose. Journal of Textile Research, 2006, 01: 86-88.

3. Z. Zhao, Md. Hasab, Ikbal, W. Li: The development of the Knitting Machine and Knitting Process. Glass Fiber Reinforced Plastic/Composite Materials, 014, 10:90-95.

4. J. K. Jiang, Z. D. Fang, J. Z. Su: Optimal Designing of Helical Gear Tooth Surface Modification Based on the Minimum Transmission Error. Journal of Aerospace Power, 2013,07: 1637-1643.

5. L. D. Wang, S. Y. Ling, Y. Ma, X. D. Wang, Z. F. Lou: The Processing Method of Precision and Ultra-precision Cylindrical Gear. Optics and Precision Engineering, 2009,02: 321-326.

6. Krantz T L. A Method to Analyze and Optimize the Load Sharing Split Path Transmissions. San Diego: NASA Technical Memorandum107201, 1996: 1-10. 
7. Ahmet. Load Sharing Characteristics of Planetary Transmission. Mech Mach Theory, 1994, 29(8): 1151-1161.

8. B.Li: Analyze the Method of Load Sharing Coefficient of Planetary Gear (MS., Nanjing University of Aeronautics and Astronautics, China 2005), pp.13-17.

9. Hidaka Teruaki, Yamamoto Nobuyuki and Takeshi Ishida: Japan Machinery Association proceedings (Tokyo, Japan, November 8-10, 1986). Vol. 52, pp.2200-2206. 